\title{
Research on Greening Design Based on Urban Landscape
}

\author{
Zheng Jia-Xin ${ }^{1}$, Tu Hao-Ran ${ }^{1}$, Lee Kun-Fa ${ }^{1 *}$ \\ ${ }^{1}$ Jiangxi Applied Technology University, Nanchang, Jiangxi, China
}

\begin{abstract}
Garden landscape is the basic construction of a city, which can effectively improve the ecological environment of a city, highlight the urban cultural characteristics and the quality of life of the residents. The landscape design project uses the internal space of the garden to improve the quality of the city, protect the ecological environment, improve the greening of the city and improve the quality of the urban living environment, and continue to develop green landscapes to improve the urban environment and improve the living comfort of living.
\end{abstract}

\section{Introduction}

With the improvement of health consciousness, the requirements for living environment have become higher and higher, and the construction of urban gardens has become the focus of urban construction in China. It plays a very important role in urban garden landscape design and maintenance management, improving the urban environment and improving the quality of life. So comprehensive design of urban landscape, Improve garden vegetation diversity and landscape level, Improve Ecological Benefits with Ecological Protection ${ }^{[1]}$ Area, expanding the space where people and nature are integrated [8].The planning and design of garden greening landscape is not simply planting flowers and trees, but using various methods of landscape design to reasonably mix plants, sketches, garden roads and other elements. Create more comfortable leisure space, let the comfort, beauty and charm of nature still be felt in the bustling city ${ }^{[2]}$. The design of garden landscape should be based on protecting the ecological environment and improving the living environment. The natural landscape and the human landscape should be closely linked. It should be carried out from the three aspects of garden green planting design points, garden road design points and garden road sketch design. The elaboration (Fig 1) is helpful to the planning and design of landscaping, as described below:

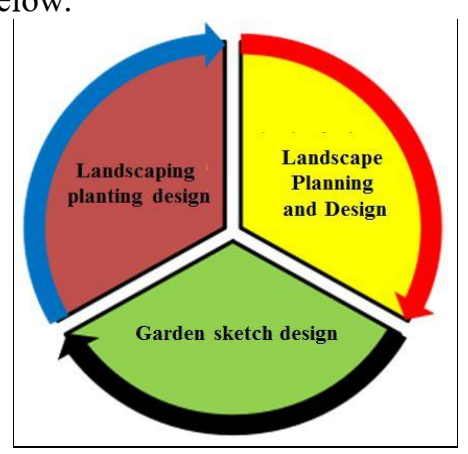

Fig. 1. Planning and design of landscaping.

\subsection{Planting design of garden and green space}

The green space is composed of plants, there are many types of plants in China, different types of plants are suitable for planting in different areas. The spacing of the planting design is strictly controlled when planting. From the final plan of green space planning and design, there are a lot of documents and materials, which are very useful in the later garden management. Therefore, analyze, collect, arrange and store the relevant information on the green soil, such as the survey data of the garden site, the plant variety configuration data, and the maintenance management manual. In the later garden management, it is possible to effectively prevent and formulate preventive measures against possible problems.

\subsection{Planning and design of garden road}

Garden greening landscape planning and design The design of the width of the garden road is divided into main roads, branch roads, and footpaths. Due to the large number of pedestrians in the park, the width of the main road is generally controlled between 4 and 6 meters, and the design of the road should be uniform. The road paving should be uniform; the branch road is the backbone of the park's various attractions. Scenic spots are connected in series. Generally, the width of a branch of a single line is between 0.8 and $1.0 \mathrm{~m}$, the width of a branch of a double line is between 1.2 and $1.8 \mathrm{~m}$, and the width of a branch of a three-way line is between 1.8 and $2.2 \mathrm{~m}$. The footpath is a relatively artistic road in the park, and it is a shortcut between various attractions. The width of the footpath is generally 0.8 to $1.0 \mathrm{~m}^{[4]}$. That is to say, the planning and design of garden greening landscapes must not only create comfortable and entertaining spaces for people, but also satisfy people's curiosity about the landscape. When designing garden roads, the principle is usually tortuous, giving people a sense of winding paths. In the vast space, squares and fountains are designed to provide a place for people to 
distribute and relax. The buildings are integrated in the garden, so that people are in the landscape of nature. Designing landscape garden planning land through vertical design can reduce the amount of earthwork excavation and backfilling during construction. Use the undulations of the terrain to design the park road to form a relatively hidden space in the park, allowing people to walk on the park road and feel the changes in the surrounding landscape, forming a feeling that is nonexistent, highlighting the changes in the landscape and vertical roads in the connected places.

\subsection{Garden sketch design}

Dumpster settings are convenient for people to throw garbage, therefore, it should be set in the rest area, the shopping area, and the square distribution area. The number can be determined according to the capacity of the park. The garden has a fountain as a backdrop, not only moisten the surrounding air, lowering the atmospheric temperature brings a cooler experience to people, can also increase the visibility of the park, the design of the fountain can combine the surrounding squares, buildings and plants to create a romantic atmosphere. The design of garden lights should be arranged according to the overall plan of the park. The lamps generally set at the entrance of the garden, around the garden road and around the distribution square. The height of the garden lamp is controlled between $5 \sim 10 \mathrm{~m}$, and the distance is controlled between $35 \sim 110 \mathrm{~m}$. In addition to the role of garden lights, It should also be enjoyable, combining the terrain and landscape of the park, choosing different appearance garden lights, set different shapes of floor lamps on the lawn to increase the level of the night landscape. In general, the brightness of garden lights needs to be different according to location and area. It is designed to be bright, soft, and dazzling according to the landscape, adding different layers of beauty to the landscape of the park.

Basically, urban garden greening landscape design and conservation urban garden landscape design must adhere to the basic principles of " harmony, nature, economy", and the comprehensive allocation of various vegetation, so that the entire garden landscape becomes a balanced ecosystem, while strengthening conservation management to ensure the healthy growth of vegetation, certain basic principles must be adhered to in the design of urban garden landscapes, that is, the coordination between urban garden landscapes and the surrounding environment, and the style of plants must be designed with the garden landscapes. The overall budget must be unified and the economic costs must be controlled. The scientific design of the garden structure reflects the actual function, greening effect and optimization of the layout. Keep a certain safety distance between the green belt and the building. According to the climate conditions in different seasons, the plants should be selected according to the climate conditions in different seasons, which reflects the local characteristics and realizes the diversity of ecological gardens. In terms of construction technology, it is necessary to pay attention to the topography of the construction site, determine the planting location to create excellent landscape works, maintain the natural characteristics of the trees themselves, and show the irregularity of the trees as much as possible, making the construction of the garden landscape more natural.

\section{Countermeasures for the development of urban landscape gardening}

For the development of urban landscape gardening, a complete countermeasure must be formed from planning ${ }^{[3]}$, development, design and design. The analysis is as follows (Fig. 2):

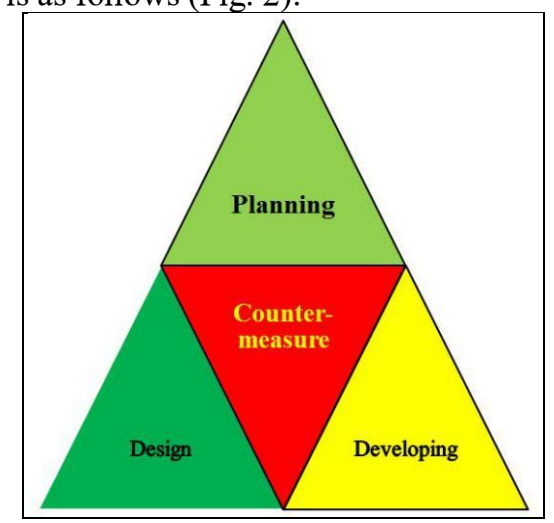

Fig. 2. Development countermeasures for urban landscape gardening.

\subsection{Improve urban greening planning}

The center of construction is planning. The key to a new breakthrough in urban greening lies in a forward-looking scientific urban green space system planning. According to the current urban development situation, combine the city's existing landscape features, the protection of historical and cultural cities, and the emergency refuge functions of public green spaces, formulate the urban green space system plan, and define the near-term development goals. To adjust the agricultural industry structure, construct high-standard regional greening isolation zones between urban groups, industrial areas and living areas, highlighting the independence of each district. Utilize mountainous areas, water surfaces, seashores, beaches, and rivers around the city to plan and build large areas of forests around the city, ecological corridors along rivers and roads, and efficient farmland forest networks, make full use of suburban natural landscapes, and build scenic woodlands and nature protection Area, expanding the space where people and nature are integrated ${ }^{[6]}$. It is necessary to plan and build large nurseries, flower production bases, and flower markets around the city, and encourage and support suburban farmers to develop seedlings, flower industries, and urban-rural integration for common development. 


\subsection{Actively explore the development of roof greening}

Because the investment in roof greening is much higher than that in flat land,and the later maintenance costs are also higher than flat land greening, Therefore, first of all, it is necessary to clarify the mandatory index requirements for the development of roof greening in policy. Secondly, the establishment of encouraging provisions of design and green space rate to mobilize the initiative and enthusiasm of development units. In addition, several government development and construction demonstration projects have been established.

\subsection{Adapt to local conditions, optimize greening design}

According to the different characteristics of the city to carry out different greening design, highlight the cultural heritage and connotation of the city ${ }^{[7]}$. Focus on the city's main intersections and bustling streets, create a number of human landscapes, and combine urban greening with distinctive urban sculptures, architectural sketches, and recreational facilities to showcase the city's rural customs and enhance the city's taste. The new urban area is dominated by large-scale green planting. However, due to the limited area of green space in the old city, its greening construction should be mainly based on reconstruction, combined with the needs of urban residents' activities and leisure, to make refinements and create different urban greening styles ${ }^{[8]}$. Reasonably arrange green tree species, and vigorously promote the use of native tree species with low cost, strong adaptability, and distinctive local characteristics, and preferentially choose plants that are resistant to drought, water, and easy to maintain.

\subsection{Do a good job in greening maintenance}

The current maintenance operation mode is still simple and primitive, mainly weeding, watering, spraying, neglecting the art of pruning, fertilization, and prevention of diseases and insect pests ${ }^{[5]}$. The result directly affects the greening landscape effect and causes trees. Poor growth and single shrub reshaping, so it is equally important to pay attention to the quality of greening construction as well as the quality of conservation.

\section{The main reasons for building urban gardens are}

\subsection{Requirements for protecting ecology and environment}

Rapid development after industrialization and urbanization, People are surprised that our environment has become so bad, Ecological imbalance, air, water and soil pollution, Extinction of plants and animals, soil erosion, desertification, greenhouse effect, etc., reduce the quality of human life, various "urban diseases" then threaten human health. These have prompted humans to realize that they must turn from the black road of industrialization to the green road of sustainable development. The construction of a garden city will allow humans and nature to develop in harmony and maintain biodiversity.

\subsection{Requirements for developing national cultural features}

Due to the rapid development of information dissemination and network, the trend of cultural internationalization has intensified. The standardization and commodification of cities and buildings have gradually disappeared the characteristics of buildings and cities. The appearance of cities is the same and the context is difficult to inherit. This is a cultural loss. Because the garden is closer to people's lives, it carries a lot of historical and cultural accumulation, reflecting the local natural and cultural landscape. The materials used to construct the garden, such as plants and rocks, have more local characteristics, which is more conducive to the development of national and local The effect. Chinese gardens have a long history and cultural traditions and characteristics, and many different local schools and national styles have emerged during the development process. These traditional characteristics should be inherited and developed well. With the advancement of the times, creating gardens with the spirit of the times, which meets the basic needs of modern people, and has national and local cultural characteristics, is the call of gardeners for the times.

\subsection{Adapt to local conditions, optimize greening design}

Urbanization is the result of economic development and the increase of the degree of urbanization, and it will promote the development of urban economy. A city is a place with a large population, and the ecological environment of the city has a profound impact on the physical and mental health of citizens. Therefore, the construction of garden cities is becoming more and more important.

\subsection{China is entry into an aging society}

According to statistics from the National Bureau of Statistics from 2015 to 2018 (Fig. 3), in 2015, 22 million people were aged 60 years and over, accounting for $16.1 \%$ of the total population, and 14.386 million people were 65 years old and above, accounting for $10.5 \%$. In 2016, the population aged 60 and over was 230.86 million, accounting for $16.7 \%$ of the total population; the population aged 65 and over was 15.03 million, accounting for $10.8 \%$ of the total population. In 2017 , the population aged 60 years and over was 240.9 million, accounting for $17.3 \%$ of the total population, and the population aged 65 and over was 15.831 million, 
accounting for $11.4 \%$ of the total population. In 2018 , there were 249.49 million people aged 60 and over, accounting for $17.9 \%$ of the total population, and 165.65 million people aged 65 and over, accounting for $11.9 \%$ of the total population. In China, 130 million people are over 60 years old, accounting for $10 \%$ of the total population; by 2020 , this ratio will reach $16 \%$, entering the ranks of elderly countries. The aging society has also put forward more requirements for gardens: from the distribution of parks and green spaces and the radius of services to the layout and facilities in the park, they must be able to meet the needs of the elderly for walking, fitness, entertainment, leisure and communication Create an environment conducive to the physical and mental health of the elderly. According to the statistics of the National Bureau of Statistics (Fig. 4), in 2018, China 's population in terms of age composition, the working-age population between the ages of 16 and 59 was 89.729 million, accounting for $64.3 \%$ of the total population; the population aged 60 and over It is 249.49 million people, accounting for $17.9 \%$ of the total population, of which 165.65 million people are 65 years old and above, accounting for $11.9 \%$ of the total population

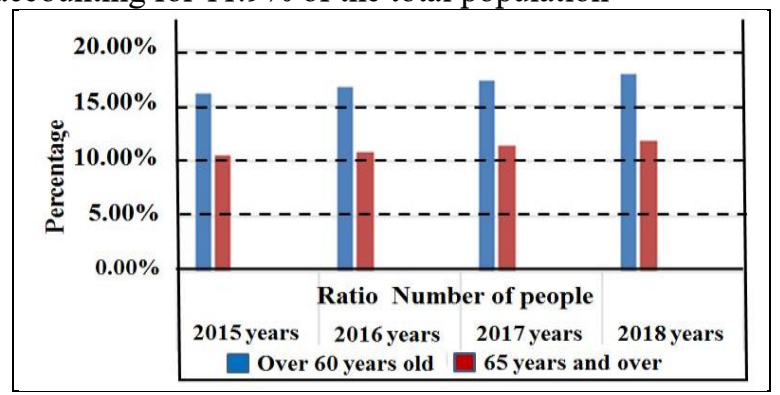

Fig. 3. Statistics of the ages of 60 and 65 in 2015 and 2018.

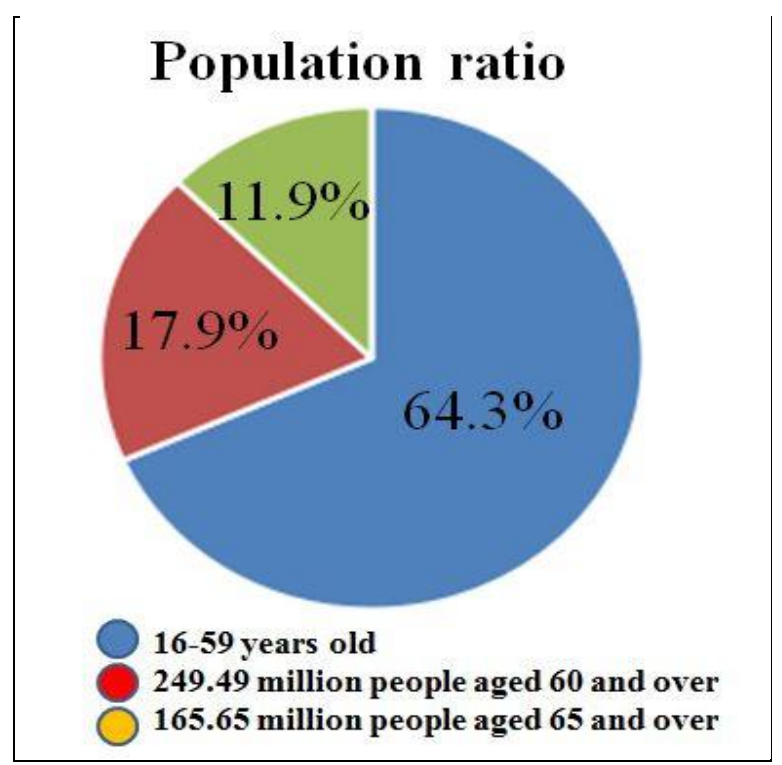

Fig. 4. Age composition of China's population in 2018.

\subsection{China is entry into an aging society}

Shortened working hours and increased leisure time With the economic growth and advancement of science and technology, labor production efficiency has increased, working hours have been shortened, and people's leisure time has increased. Tense and fast-paced work make people urgently need to make good use of their free time to relax and eliminate fatigue. This requires gardeners to jump out of the fence of small gardens and expand into the area of scenic spots to meet people's urgent needs for green and natural environment.

The role played by the garden city is to take the improvement of the urban ecological environment as the first task. The garden city is a total of various forms and functions of parks and green spaces. No matter what form and function of the parks and green spaces, the improvement of the urban ecological environment as one of its primary functions, it should have a high rate of garden green space, and its standards should be based on the ability to maintain urban ecological balance. It is necessary to speed up the construction of garden green space to meet the needs of improving the urban ecological environment. Not only must parks and green areas be developed in densely populated urban centers, but parks, green areas, scenic areas, and ecological woodlands in the suburbs must also be vigorously developed.

\section{Conclusion}

All in all, urban garden landscape is a technically tedious and powerful project. The construction personnel are required to have good professional skills, strictly control the process and key procedures, ensure that the content meets the requirements of garden landscape design, and give full play to the important role of garden landscape in improving the urban ecological environment.

This is also the increasing attention of urban people to the design of landscaping and greening. At the same time, designers are expected to design high-quality landscaping landscapes, while satisfying the pursuit of nature by urban people, improving the quality of living environment of urban people, and improving the global city. The quality of the ecological environment guarantees the sustainable development of human health.

\section{References}

1. Lsis of design points of garden greening [J]. Jiangxi Building Materials, 2015 (4): 189-195.

2. Ni Shaona. Analysis of garden greening landscape design and maintenance management strategy [J]. Modern Horticulture, 2014 (14): 100.

3. Li Tianqiang. Urban garden greening landscape design and maintenance management [J]. Jiangxi Building Materials, 2019 (21): 192.

4. Sun Yalin. Exploration of garden landscape construction and road greening maintenance management strategies [J]. Modern Horticulture, 2018 (16): 198-199.

5. Liang Zhihe, He Xinjian. Analysis of common problems and preventive methods of garden 
engineering [J]. Green Environmental Protection Building Materials. 2017, (2): 35.

6. Lin Shusheng. Analysis of key points of construction management of garden landscape engineering [J]. South Agricultural Machinery, 2017 (15): 43-44.

7. Teng Yue. Problems and Countermeasures of Garden Plant Conservation [J]. Agricultural Development and Equipment, 2018 (9)

8. Xu Guohua, Chen Dan, Qiu Yanhong. Analysis of conservation-oriented garden greening maintenance technology $[\mathrm{J}]$. Agricultural Science and Technology, 2016 (9): 124-125. 